\title{
Analisis Kebutuhan Modul Elektronik Mata Pelajaran IPS Untuk Siswa SMP
}

\author{
Mutiara Danirmala ${ }^{10}$, Asrowi1 $^{11}$, Akhmad Arif Musadad ${ }^{12}$ \\ danirmalamutia@gmail.com
}

\begin{abstract}
This research is a preliminary research with the aim to determine the needs of the students of SMP Islam Diponegoro regarding the media that need to be developed for social studies teaching and learning process. The method used in this research is survey method. The data analysis technique used was descriptive qualitative. Based on interviews and observations that have been conducted, it can be seen that the amount of material, the limited amount of learning resources, and the use of monotonous media are all obstacles in the social studies teaching and learning process. The results of the questionnaire given to students showed that as many as $54 \%$ of students need an electronic module as their learning media, and about $66 \%$ of the students stated that the nature condition of Indonesia is a difficult material. Therefore, the development of instructional media in the form of electronic module is needed as a tool to communicate the subject material interactively and achieve the goals of learning. The electronic module can be developed supported by the school facilities and can be used independently by students at home. The electronic module is the right solution that can be taken, especially for the Revolutionary Era 4.0 which encourages the learning process to integrate technology to improve the quality and efficiency of education.
\end{abstract}

Keywords: Media, Electronic Module, Social Studies Learning

\footnotetext{
10 Mahasiswa Magister Teknologi Pendidikan Universitas Sebelas Maret Surakarta

11 Universitas Sebelas Maret Surakarta

12 Universitas Sebelas Maret Surakarta
} 


\section{PENDAHULUAN}

endidikan merupakan salah satu faktor penentu kemajuan bangsa, karena pendidikan mampu menghasilkan generasi-generasi yang berkualitas. Pendidikan adalah suatu hal yang sangat penting dalam mengembangkan potensi sumber daya manusia. Pengembangan sumber daya manusia yang dimaksud salah satunya adalah dengan kegiatan pengajaran. Pasal 1 Undang-undang Republik Indonesia Nomor 20 Tahun 2003 tentang Sistem Pendidikan Nasional menyebutkan dengan jelas bahwa: Pendidikan adalah usaha secara sadar dan terencana untuk mewujudkan suasana belajar dan proses pembelajaran agar peserta didik secara aktif mengembangkan potensi dirinya untuk memiliki kekuatan spiritual keagamaan, pengendalian diri, kepribadian, kecerdasan, akhlak mulia, serta ketrampilan yang diperlukan dirinya, masyarakat, bangsa, dan negara. Pendidikan memiliki peranan yang sangat penting, dan perubahan atau perkembangan pendidikan adalah hal yang seharusnya terjadi sejalan dengan perubahan budaya kehidupan (Trianto, 2009). Upaya dalam meningkatkan kualitas pendidikan salah satunya dengan memperbaiki paradigma guru dalam melakukan kegiatan belajar mengajar. Guru harus terdorong untuk mengkonstruksi kreativitas, pemikiran kritis, penguasaan teknologi, dan kemampuan literasi digital.

Salah satu hal yang kurang menjadi perhatian guru adalah penggunaan media pembelajaran. Padahal, media memiliki peranan penting yaitu sebagai alat untuk mengkomunikasikan materi secara interaktif dan dapat membantu siswa dalam mencapai tujuan pembelajaran. Ada banyak media pembelajaran yang dapat dikembangkan oleh guru seperti bahan ajar, metode pembelajaran, strategi pembelajaran, dan lain sebagainya. Media pembelajaran yang dikembangkan, dapat digunakan guru dalam proses pembelajaran disekolah maupun digunakan siswa secara mandiri dirumah.

Salah satu media yang memenuhi kriteria sebagai pembelajaran mandiri adalah modul. Modul merupakan bahan ajar yang disusun secara matematis yang disesuaikan dengan usia siswa sehingga siswa dapat memahami bahasa maupun tingkat pengetahuannya (Prastowo, 2011). Selain itu siswa juga dapat mengukur sendiri penguasaan materi dari modul yang mereka pelajari. Media yang dapat digunakan mandiri oleh siswa akan membantu siswa dalam mempersiapkan diri pada materi yang dibahas disekolah. Modul memungkinkan siswa untuk belajar sendiri dirumah sehingga siswa tidak bergantung pada guru dalam pembelajaran.

Modul yang banyak dikenal adalah modul cetak. Modul cetak yang sering digunakan disusun secara sederhana dan berisikan soal-soal latihan sehingga cenderung bersifat informatif. Padahal, era Revolusi Industri 4.0 saat ini mendorong untuk mengintegrasikan teknologi yang nantinya akan membuat pengaruh besar dalam meningkatkan mutu dan efisiensi pendidikan. Kehadiran Teknologi Informasi ( $\mathrm{TI})$ mulai mempengaruhi penyelenggaraan pendidikan, berbagai model pengembangan pembelajaran berbasis TI menjadi pilihan yang sangat diminati (Lestari, Sunardi, \& Suryani, 2017). Penggunaan teknologi dalam pembelajaran sangat penting dan menguntungkan (Murphy \& Greenwood, 1998). Pentingnya mengintegrasikan teknologi dalam pembelajaran banyak dilaporkan seperti NCET (National Council for Educational Technology) tahun 1997 yang menyatakan bahwa teknologi informasi dengan cepat dapat mengubah dunia termasuk pada bidang pendidikan. Upaya tersebut diatas harus menjadi perhatian yang cukup serius terlebih pada era Revolusi Industri 4.0 yang menekankan pada digital economy, artificial intelligence, big data, dan robotic.

Pentingnya pengintegrasian teknologi dalam pengembangan media terutama modul elektronik sudah pernah dilakukan oleh peneliti lain seperti penelitian pengembangan oleh Perdana, dkk (2017) tentang pengembangan e-module yang menggabungkan keterampilan proses sains dan bahan gerak 
dinamis untuk meningkatkan keterampilan berpikir kritis dan meningkatkan motivasi belajar siswa SMA, Nopriyanti (2018) tentang pengembangan modul elektronik berbasis 3D pageflip professional mata kuliah gambar teknik di program studi pendidikan teknik mesin, dan Ghaliyah, Bakri \& Siswoyo (2015) tentang pengembangan modul elektronik berbasis model learning cycle $7 \mathrm{E}$ pada pokok bahasan fluida dinamik untuk siswa SMA kelas XI. Selain penelitian pengembangan, penelitian eksperimen juga dilakukan oleh Hamzah \& Mentari (2017) terkait kontribusi e-modul untuk ketrampilan proses sains. Penelitian-penelitian yang telah dilakukan tersebut menghasilkan temuan bahwa modul elektronik efektif dan dapat dijadikan salah satu media dan bahan ajar mandiri yang dapat dikembangkan dalam mencapai tujuan pembelajaran (Pratono, 2018).

Salah satu mata pelajaran yang diajarkan di Sekolah Menengah Pertama (SMP) adalah IImu Pengetahuan Sosial (IPS). IPS memiliki padanan istilah dengan social studies. IPS sering direduksi dari cabang disiplin ilmu sosial seperti geografi, sejarah, ekonomi, sosiologi, antropologi, dan sebagainya yang digunakan dalam bidang pendidikan (Daldjoeni, 1981). Pendidikan IPS terutama dalam kurikulum 2013 memiliki tujuan yang dirumuskan agar siswa memiliki kompetensi: (1) mensistematisasikan bahan, informasi, dan atau kemampuan yang telah dimiliki tentang manusia dan lingkungannya menjadi lebih bermakna, (2) lebih peka dan tanggap terhadap berbagai masalah sosial secara rasional dan bertanggung jawab, dan (3) mempertinggi rasa toleransi dan persaudaraan di lingkungan sendiri dan antar manusia (Purnomo, Muntholib, \& Amin, 2016). Berdasarkan tujuan pembelajaran IPS diatas, perlunya pemahaman terhadap sejumlah konsep dan pengembangan untuk melatih sikap, nilai, moral, dan keterampilannya berdasarkan konsep yang dimilikinya. Dengan demikian, pelajaran IPS harus memiliki pola pembelajaran yang kuat akan konsep dan menekankan pada pendidikan serta pembekalan untuk kehidupan siswa dimasa yang akan datang. Pada kenyataannya, pembelajaran IPS yang terjadi disekolah tidak demikian. Pemahaman konsep-konsep lebih diutamakan sehingga mata pelajaran IPS dipandang sebagai mata pelajaran yang hanya bersifat hafalan. Sebagian besar guru memberikan pembelajaran dengan metode ceramah sehingga pelaksanaan pembelajaran terpusat pada guru (Istuningsih, Baedhowi, \& Sangka, 2018).

Masalah yang terjadi dalam proses pembelajaran IPS yang berlangsung selama ini bukan hanya terbatas pada pembelajaran IPS yang tidak sesuai dengan tujuan pengajaran IPS saja. Ketersediaan media pembelajaran sebagai sumber belajar yang mempermudah siswa juga masih sangat minim. Siswa hanya memperoleh materi dari buku teks dan masih sangat bergantung pada guru. Guru kesulitan membuat alat peraga atau mengembangkan media pembelajaran sehingga kesulitan dalam memberikan contoh visual kepada siswa (Tri, Suryani, \& Sunardi, 2016). Dengan demikian, pembelajaran IPS tidak menarik, efektif, dan efisien. Tujuan penelitian ini adalah untuk mengetahui kebutuhan siswa SMP Islam Diponegoro terkait media pembelajaran yang perlu dikembangkan untuk pelajaran IPS. Hasil dari penelitian ini diharapkan dapat memberikan informasi awal mengenai kebutuhan siswa akan pengembangan media pembelajaran pada pelajaran IPS yang nantinya dapat dilakukan penelitian lanjutan terkait hal tersebut.

\section{METODE PENELITIAN}

Penelitian ini dilaksanakan di SMP Islam Diponegoro Surakarta yang beralamat di Jln. Kapten Mulyadi No.221D, Pasarkliwon, Kota Surakarta. Populasi penelitian adalah seluruh siswa kelas VII SMP Islam Diponegoro Surakarta yang berjumlah 73 siswa. Sampel dipilih secara acak sebanyak 36 siswa. Teknik pengumpulan data yang digunakan adalah wawancara, observasi dan angket. Instrumen 
pengumpulan data dengan menggunakan lembar observasi dan angket. Lembar observasi digunakan untuk memperoleh data tentang kegiatan pembelajaran IPS. Angket yang digunakan berupa angket terbuka yang disusun sendiri oleh peneliti dengan kolom alasan agar responden bebas menjawab. Indikator yang dikembangkan dalam angket didasarkan pada kebutuhan media yang diinginkan siswa (jenis media, dan karakteristik media) serta materi pelajaran kelas VII yang sulit dan banyak. Data hasil penelitian dianalisis secara deskriptif kualitatif.

\section{HASIL DAN PEMBAHASAN}

Berdasarkan hasil wawancara dan observasi pada pembelajaran IPS diperoleh data tentang pembelajaran IPS di SMP Islam Diponegoro Surakarta. Selain wawancara dan observasi, angket terbuka juga disebarkan kepada siswa terkait kebutuhan media yang diinginkan dan materi yang diperlukan serta dianggap sulit oleh siswa pada pelajaran IPS.

\section{Implementasi Pembelajaran IPS}

Implementasi pembelajaran IPS di SMP Islam Diponegoro Surakarta diperoleh dari observasi dan wawancara yang telah dilakukan. Hasil wawancara dan observasi pembelajaran IPS disekolah dirangkum dalam Tabel 1.

Tabel 1. Hasil Wawancara dan Observasi Pembelajaran IPS

\begin{tabular}{ll}
\hline No & \multicolumn{1}{c}{ Hasil Observasi dan Wawancara } \\
\hline 1 & IPS dianggap sebagai mata pelajaran yang bersifat hafalan sehingga kurang menarik \\
\hline 2 & Siswa kurang antusias dan pasif dalam proses pembelajaran \\
\hline 3 & $\begin{array}{l}\text { Media pembelajaran yang digunakan terbatas karena kurangnya waktu dan SDM dalam } \\
\text { mengembangkan media pembelajaran }\end{array}$ \\
\hline 4 & Guru sebagai sumber belajar utama \\
\hline 5 & Siswa kesulitan belajar dirumah \\
\hline 6 & Fasilitas sekolah terkait ketersediaan komputer belum dioptimalkan \\
\hline
\end{tabular}

Berdasarkan Tabel 1, hasil observasi dan wawancara pada guru mata pelajaran IPS, secara garis besar menunjukkan bahwa pembelajaran IPS yang berlangsung disekolah kurang menarik. Observasi yang dilakukan selama proses pembelajaran IPS di SMP Islam Diponegoro Surakarta, diperoleh informasi bahwa implementasi pembelajaran IPS tidak sesuai dengan tujuan pembelajaran IPS yang seharusnya. Pembelajaran yang dilakukan disekolah hanya berupa penanaman konsep yang bersifat hafalan. Hal tersebut mengakibatkan rendahnya ketertarikan siswa, respon, antusias dan motivasi siswa dalam mengikuti pembelajaran IPS di sekolah. Banyak siswa kurang fokus dan belum berpartisipasi aktif dalam proses pembelajaran. Siswa cenderung diam ketika diberi kesempatan untuk bertanya atau menjawab pertanyaan. Hanya beberapa siswa yang aktif atau dominan dikelas.

Masalah lain yang ditemui yaitu guru IPS menyadari akan terbatasnya penggunaan media dalam kegiatan pembelajaran. Kurangnya waktu dan sumber daya manusia dalam pengembangan media pembelajaran menjadi hal yang mendasar. Guru hanya menggunakan buku teks dengan cakupan materi yang masih sangat umum dan latihan soal yang sederhana. Buku teks disusun dengan bahasa yang kurang komunikatif sehingga siswa sulit untuk memahami materi, terlebih ketika digunakan oleh 
siswa dirumah. Siswa juga tidak dapat mengukur kemampuannya terkait materi atau konsep yang disajikan dalam buku teks. Keadaan tersebut membuat siswa banyak yang belum memiliki kesiapan untuk belajar terutama pada pelajaran IPS. Pembelajaran juga berlangsung satu arah. Guru masih menjadi sumber belajar utama dan belum banyak dimaksimalkan oleh siswa dengan baik karena siswa cenderung malu atau malas untuk bertanya hal-hal yang sulit dipahami. Akibatnya tujuan pembelajaran tidak dapat tercapai.

Observasi fasilitas sekolah tentang ketersediaan komputer juga sudah dilakukan. SMP Islam Diponegoro memiliki laboratorium dengan ketersediaan komputer yang sangat memadai. Fasilitas tersebut dapat digunakan untuk menunjang pembelajaran. Penggunaan komputer selama ini hanya terbatas pada pelajaran TIK saja dan belum dimanfaatkan secara maksimal untuk pelajaran yang lain. Idealnya, sesuai dengan tuntutan kurikulum 2013, pembelajaran di sekolah sudah mengintegrasikan pembelajaran menggunakan media berbasis teknologi dan informasi. Pengintegrasian teknologi dalam pembelajaran di sekolah sangat penting dilakukan terlebih pada era revolusi industry 4.0. Media pembelajaran dengan menggunakan teknologi dapat menarik minat serta motivasi siswa untuk belajar.

\section{Kebutuhan Media Pembelajaran Siswa}

Kebutuhan terkait media pembelajaran yang diinginkan siswa diperoleh dari angket terbuka yang telah dibagikan. Hasil angket tentang kebutuhan media yang diinginkan siswa disajikan dalam Tabel 2.

Tabel 2. Kebutuhan Media Pembelajaran Siswa

\begin{tabular}{rlc}
\hline No & Jenis Media yang Diinginkan Siswa & Jumlah (\%) \\
\hline 1 & Slide & $23 \%$ \\
\hline 2 & Modul Elektronik & $54 \%$ \\
\hline 3 & Handout & $6 \%$ \\
\hline 4 & LKS & $17 \%$ \\
\hline
\end{tabular}

Tabel 2 menginformasikan hasil angket terkait jenis media yang diinginkan siswa dalam pembelajaran IPS. Media pembelajaran penting untuk dikembangkan tentunya sesuai dengan kebutuhan siswa. Dalam hal ini, angket tentang keinginan dan kebutuhan siswa terkait media pembelajaran telah dibagikan. Empat media yang dapat dipilih siswa untuk dikembangkan terdiri dari slide, modul elektronik, handout, dan LKS. Sebanyak 54\% siswa dari 36 siswa memilih modul elektronik sebagai media yang perlu dikembangkan dalam pembelajaran IPS. Data dari hasil angket dapat diketahui bahwa siswa menginginkan adanya pengembangan media pembelajaran yang memudahkan siswa belajar dan dapat digunakan disekolah maupun dirumah.

Modul elektronik memiliki karakter yang berbeda dan menarik. Penyusunan modul elektronik dapat dirancang dengan ditambahkan video atau gambar-gambar untuk memperjelas sebuah konsep. Modul elektronik juga disesuaikan dengan kurikulum yang berlaku, dan dirancang berdasarkan kebutuhan siswa. Bahasa yang digunakan pada modul elektronik mudah dipahami oleh siswa dan berisikan soal-soal latihan. Hal tersebut dapat membantu siswa mengetahui kemampuannya sendiri dalam memahami konsep yang nantinya dapat diterapkan dalam kehidupan. Modul elektronik tersebut dapat mengembangkan potensi siswa menjadi pembelajar mandiri. Siswa dapat terbantu dengan 
adanya sumber belajar dalam upaya meningkatkan kompetensi atau pemahaman materi serta tidak bergantung pada pada satu sumber informasi saja.

\section{Materi Pelajaran IPS di SMP}

Modul elektronik yang akan dikembangkan mengacu pada materi yang banyak dan sulit. Hasil angket terkait materi disajikan dalam Tabel 3.

Tabel 3. Materi yang Dianggap Sulit

\begin{tabular}{cll}
\hline No & Materi yang Dianggap Sulit & Jumlah (\%) \\
\hline 1 & Ruang dan Interaksi Antarruang & $3 \%$ \\
\hline 2 & Potensi Sumber Daya Alam & $23 \%$ \\
\hline 3 & Dinamika Penduduk & $9 \%$ \\
\hline 4 & Kondisi Alam Indonesia & $66 \%$ \\
\hline
\end{tabular}

Materi pelajaran IPS SMP secara garis besar memiliki cakupan yang luas. Materi pelajaran yang terdapat di buku teks yang banyak digunakan guru masih bersifat umum belum dibahas secara mendalam terutama pada materi-materi yang banyak dan sulit. Berdasarkan Tabel 3, dapat diketahui bahwa dari empat materi yang terdapat dalam pelajaran IPS kelas VII kurikulum 2013 sebanyak 66\% siswa memilih materi kondisi alam Indonesia sebagai materi yang banyak dan sulit. Materi ini memuat keadaan fisik Indonesia, potensi serta aplikasinya dalam kehidupan sehari-hari. Pemilihan materi sulit dalam modul elektronik yang akan dikembangkan akan memenuhi kebutuhan siswa terkait media pembelajaran pada pelajaran IPS. Materi tersebut juga diperlukan pemahaman kognitif dan konsep yang kuat tetapi juga adanya pendidikan dan pengembangan agar siswa dapat menerapkan konsepnya pada masalah-masalah dalam kehidupan siswa sesuai dengan tujuan pengajaran IPS. Materi ini apabila disajikan sesuai dengan kompetensi yang diharapkan dapat dijadikan bekal untuk kehidupan siswa dimasa yang akan datang seperti dalam menentukan sikap, nilai, moral dan ketrampilannya.

Modul elektronik yang akan dikembangkan mengacu pada model ADDIE yang terdiri dari tahap Analysis, Design, Development or Production, Implementation or Delivery and Evaluations untuk menghasilkan produk pembelajaran berupa modul elektronik yang dapat dimanfaatkan dalam proses pembelajaran IPS.

\section{KESIMPULAN DAN SARAN}

Berdasarkan data hasil penelitian dan pembahasan yang telah dilakukan dapat disimpulkan bahwa kendala yang dihadapi pada pembelajaran IPS di SMP Islam Diponegoro adalah kurangnya pengembangan media pembelajaran. Pengembangan media pembelajaran yang sesuai dengan analisis kebutuhan siswa SMP Islam Diponegoro adalah modul elektronik. Modul elektronik dipilih sebagai solusi dari kendala yang terjadi pada pembelajaran IPS. Modul elektronik disusun dengan menarik, bahasa yang komunikatif dan materi yang sesuai sehingga dapat memudahkan siswa dalam belajar. Siswa dapat mengukur sendiri kemampuannya terkait materi yang disajikan dalam modul elektronik dan 
siswa dapat menggunakannya disekolah maupun dirumah. Penggunaan dan kesiapan guru dalam menggunakan media berbasis teknologi ini relatif baik untuk meningkatkan pembelajaran. Hal ini bisa dilihat dari ketersediaan fasilitas berupa laboratorium komputer di sekolah studi. Berdasarkan kondisi tersebut, pengembangan modul elektronik mata pelajaran IPS untuk siswa SMP penting untuk dilakukan penelitian lanjutan dan diuji efektivitasnya.

\section{DAFTAR PUSTAKA}

Astuti, T., Suryani, N., \& Sunardi. (2016). Pengembangan multimedia pembelajaran interaktif pada mata pelajaran IPS di Sekolah Dasar (SD) Muhammadiyah program unggulan Colomadu Karanganyar. Teknodika, 15(2), 62-71.

Daldjoeni. (1981). Dasar-Dasar Ilmu Pengetahuan Sosial, Buku Pengantar Bagi Mahasiswa dan Guru. Bandung: Penerbit Alumni.

Ghaliyah, S., Bakri, F., \& Siswoyo. (2015). Pengembangan Modul Elektronik Berbasis Model Learning Cycle 7E Pada Pokok Bahasan Fluida Dinamik Untuk Siswa SMA Kelas XI. Prosiding Seminar Nasional Fisika (E-Journal) SNF2015, 4, pp. 149-154. Jakarta: Jurusan Fisika Fakultas MIPA Universitas Negeri Jakarta

Hamzah, I., \& Mentari, S. (2017). Development of accounting e-module to support the scientific approach of students grade $X$ vocational high school. Journal of Accounting and Business Education, 2(1), 78-88.

Istuningsih, W., Baedhowi, \& Sangka, K. B. (2018). The effectiveness of scientific approach using emodule based on learning cycle 7E to improve students' learning outcome. International Journal of Educational Research Review, 3(3),75-85

Lestari, E., Sunardi, \& Suryani, N. (2017). Pengaruh penggunaan media berbasis informasi technology pada pembelajaran IPA Terhadap prestasi belajar ditinjau dari kemandirian belajar. Teknodika, $15(1), 16-25$.

Murphy, C., \& Greenwood, L. (1998). Effective intergration of information and communication technology in teacher education. Journal of Information Technology for Teacher Education, 7 (3), 413-429.

Nopriyanti. (2018). Pengembangan modul elektronik berbasis 3D Pageflip Professional mata kuliah gambar teknik di program studi teknik mesin. Jurnal Dinamika Vokasional Teknik Mesin, 3(1), 6475 .

Perdana, A. F., Sarwanto, Sukarmin, \& Sujadi, I. (2017). Development of e-module combining science process skills and dynamics motion material to increasing critical thinking skills and improve student learning motivation senior high school. International Journal of Science and Applied Science: Conference Series, 1(1), 45-54.

Prastowo, A. (2011). Panduan Kreatif Membuat Bahan Ajar Inovatif. Jogjakarta: Diva Press. 
Pratono, A. (2018). Contribution of assisted inquiry model of e-module to students science process skill. Journal of Innovative Science Education, 7(1), 62-68

Purnomo., Muntholib., \& Amin. (2016). Model pembelajaran ilmu pengetahuan sosial (IPS) pada materi kontroversi (controversy issues) di SEKOLAH MENENGAH PERTAMA (SMP) Kota Semarang. Jurnal Penelitian Pendidikan, 33(1), 13-25.

Trianto. (2009). Mendesain Model Pembelajaran Inovatif Progresif. Surabaya: Kencana. 